\title{
DETECTING CONTAMINANTS IN POST-CONSUMER PLASTIC PACKAGING WASTE BY A NIR HYPERSPECTRAL IMAGING-BASED CASCADE DETECTION APPROACH
}

\author{
Giuseppe Bonifazi ${ }^{1,2, *}$, Riccardo Gasbarrone ${ }^{1}$ and Silvia Serranti ${ }^{1,2}$
}

${ }^{1}$ DICMA, Department of Chemical Engineering, Materials and Environment, Sapienza - University of Rome, via Eudossiana 18, 00184, Italy

${ }^{2}$ Research Center for Biophotonics - Sapienza, University of Rome, Corso della Repubblica 79, 04100 Latina, Italy

Article Info:

Received:

15 December 2020

Revised:

9 March 2021

Accepted:

12 March 2021

Available online:

6 June 2021

Keywords:

HyperSpectral Imaging

Near Infrared Analysis

PLSD analysis

Plastic packaging

Cascade detection

\begin{abstract}
Recycling of post-consumer packaging wastes involves a complex chain of activities, usually based on three main stages, that is: i) collection from households or recovery from Municipal solid waste (MSW), ii) sorting and, finally, iii) mechanical recycling. Among these activities contaminants detection and separation play a preeminent role. The utilization of a Near InfraRed (NIR) - HyperSpectral Imaging (HSI) based methods, along with chemometrics and machine learning techniques, can fulfill both the two previously mentioned goals. In this paper, the HSI-based sorting logics, to apply, to implement, to set up and to perform an automatic separation of paper, cardboard, plastics and multilayer packaging are investigated. The built PLSDA-based cascading classification model allows to recognize polymeric fragments from cellulosic ones and to identify multi-layer materials (i.e. laminated plastic and laminated cardboard). The misclassified fragments are constituted by laminated plastics. The set up cascade model reached in prediction a Recognition and a Reliability of 0.933 . The proposed NIR-HSI-based approach can represent an optimal, reliable and low-cost answer to systematically identify impurities and composite materials inside plastic waste streams.
\end{abstract}

\section{INTRODUCTION}

Post-consumer plastic packaging waste is one of the primary sources to recover polymers (Bonifazi et al., 2015a). The recycling of this waste involves different complex activities, involving the collection from households or the recovery from Municipal Solid Waste (MSW) of plastic packages and the further sorting and mechanical recycling to washed milled goods (Jansen et al., 2015).

The complexity of the processing phases is linked to the heterogeneity of this waste stream, mainly due to the presence of contaminants and cellulose fragments, and secondly to the presence of multi-layer materials. Those materials, for their characteristics, are difficult to separate by classical methods (i.e. gravimetric separation), thus ending up in the recovered plastics products.

The properties of waste materials, their characteristics, and physical-chemical attributes can be investigated by using sensing devices that are able to acquire objects' spectral characteristics attributable to a specific wavelength range. The further processing of these spectra can allow the identification of the object spectral signatures and their classification. This approach is currently used to set-up and develop on-line procedures aimed to recognize different materials occurring in a waste stream as they result after specific processing/selection actions (Bonifazi et al., 2009). In recent years, industrial operations concerning automated sorting of plastic packaging strongly increased thanks to technology improvement, especially that based on Near InfraRed-HyperSpectral Imaging (NIR-HSI) (Hollestein et al., 2015).

$\mathrm{HSI}$, in fact, represents an attractive solution to characterize, to control and to perform the quality control of different materials in many sectors, i.e. cultural heritage (Capobianco et Al., 2015; Agresti et Al., 2013), agricultural/ food industry (Serranti et Al., 2018a; Serranti et Al. 2018b; Kumaravelu and Gopal, 2015; Tsuchikawa and Kobori, 2015), in the pharmaceutical and chemical industry (Roggo et Al. 2007; Larrechi et Al. 2003), and more generally in analytical science (Pasquini, 2003). In recent decades, $\mathrm{HSI}$ has emerged in the recycling sector (Bonifazi et Al. 2015b; Serranti et Al. 2015; Serranti et Al. 2013; Palmieri et Al. 2014; Hu et al., 2013; Ulrici et al., 2013; Serranti et Al., 2011).

In this paper, a Near InfraRed (NIR)-based hyperspectral imaging ( $\mathrm{HSI})$ method to perform real-time identification of 
different materials occurring in a post-consumer packaging waste stream, such as the polymeric fraction, the cellulose-based fraction and the multi-layers material fraction (i.e. laminated plastics and laminated cardboard) resulting from a recycling process, is presented.

The possibility to utilize a cascade classification model based on a two-step Partial Least Squares - Discriminant Analysis (PLS-DA) to identify cellulose-based fragments from polymer/plastic-based fragments, thus recognizing laminated plastic from polymer/plastic-based fraction and laminated cardboard (i.e. Tetra Brik) from the cellulose-based fraction, is explored (Figure 1).

\section{MATERIALS AND METHODS}

\subsection{Analyzed materials and sampling}

The materials were sampled from sorted output resulting from a material recovery facility (MRF) of post-consumer household plastic packaging waste, located in the Lazio region (Italy). Samples were collected from a waste bale composed of post-consumer packaging fragments, resulting from manual and semi-automatic sorting (oversize of a drum sieve separator). Ideally, the output of the sorting line should not contain paper-based material. However, the quality analysis performed on the 2D output of the facility highlighted the presence of paper-based packaging and similar material (i.e. laminated card): about $3.5 \%$ in weight of the analyzed material consists of paper-based packaging fragments. Coning and quartering method was used to reduce the sample size to collect. The amount of material collected was about $5 \mathrm{~kg}$ (i.e. 426 fragments). 81 particles were then selected from this pool in order to represent the typical fragments usually belonging to this fraction. For calculating the sample size (i.e. number of investigated par- ticles) was used the simplified Yamane's (1967) formula:

$$
n=\frac{N}{1+N\left(e^{2}\right)}
$$

where $n$ is the number of sampled particles, $N$ is the total number of particles constituting the collected material, and e represents the level of precision. A $90 \%$ confidence level was assumed for this equation. The fragment size ranges from 2 to $10 \mathrm{~cm}$.

Paper, cardboard and plastic. In order to build a model able to recognize paper-based fragments from polymer-based particles, 40 mixed plastic polymer-based and paper-based particles were used as a training set(Figure 2): 24 plastic/polymer-based particles (including laminated plastic) and 16 paper-based particles (including laminated card and paper).

A total of 30 particles were used as a validation set, subclustered in two sets: "Validation set 1" and "Validation set 2" (Figure 3). Sixteen particles were included in "Validation set 1": 11 plastic/polymer-based particles (including laminated plastic) and 5 paper-based particles (including laminated card and paper). While 14 particles were included in "Validation set 2": 9 plastic/polymer-based particles (including laminated plastic) and 5 paper-based particles (including laminated card and paper).

Laminated card. In order to recognize laminated from other paper-based particles, 5 paper-based particles to be included in the calibration set were additionally analyzed (Figure 4). Laminated plastic. To set-up a model able to discriminate laminated plastic from other polymer-based particles, 6 laminated plastic fragments were included in the calibration set (Figure 5).

\subsection{HyperSpectral Imaging system and data han- dling}

HyperSpectral Imaging (HSI) is a technique, based on a specific sensing architecture, that allows to digitally collect

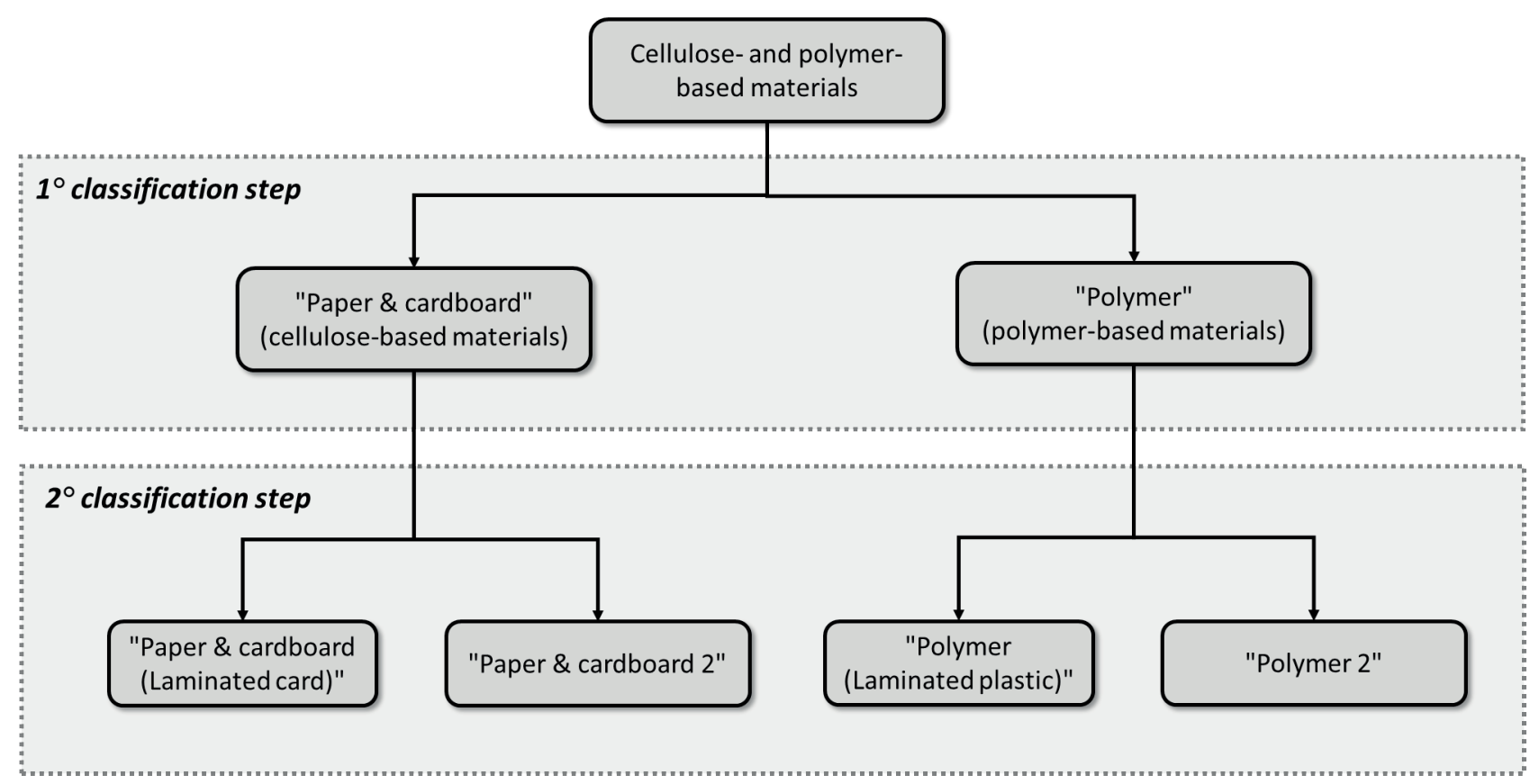

FIGURE 1: Decision tree describing the two-stage cascaded classifier applied to a post-consumer packaging waste stream to perform product classification. 

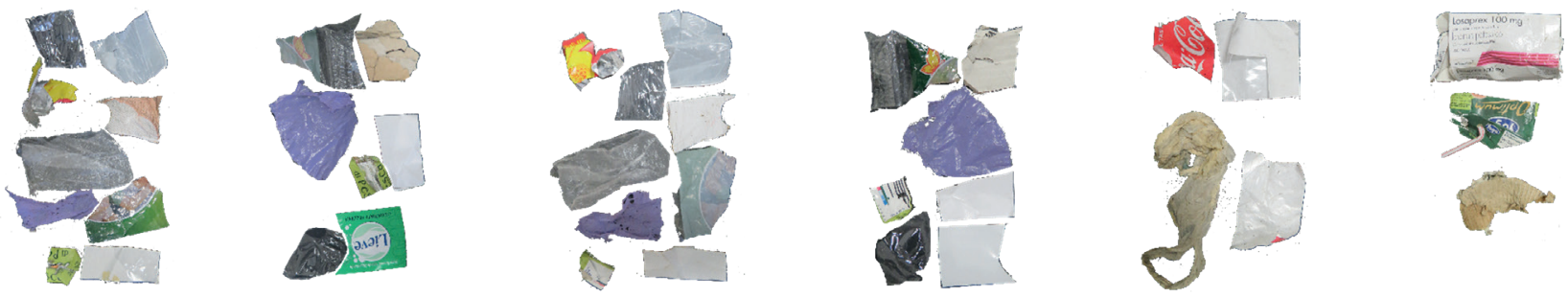

FIGURE 2: Digital images of particles included in the calibration set to build a model able to recognize paper-based fragments from polymer-based particles.

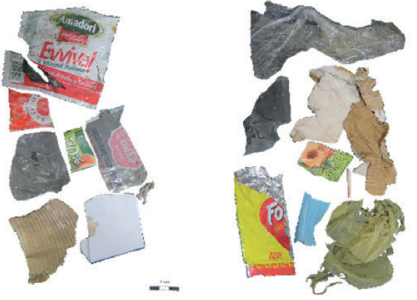

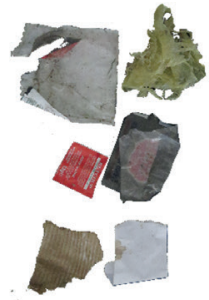

b

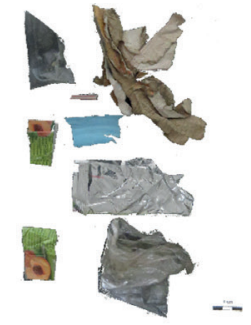

FIGURE 3: Digital images of particles included into the validation set: "Validation set 1" (a) and "Validation set 2" (b).

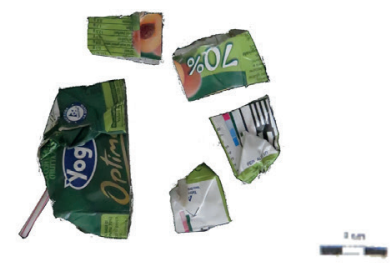

Side A

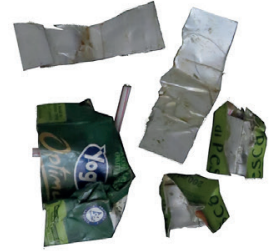

Side B

FIGURE 4: Digital images of laminated card particles. Side A: 5 fragments with the plastic/paper/metal/plastic side exposed and Side B: 4 fragments with the plastic/metal/paper/plastic side exposed.

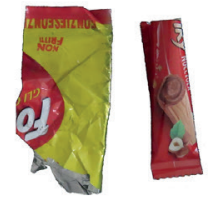

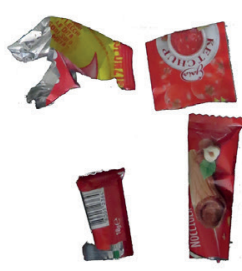

$\stackrel{\sin }{-2}$

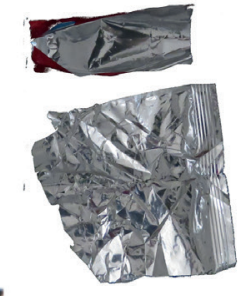

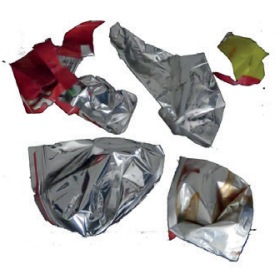

Side B

FIGURE 5: Digital images of laminated plastic particles. Side A shows the fragments with the plastic/metal side exposed, while side B the metal/plastic side.

the spectrum associated with each pixel of the collected image. The acquired information is arranged in a three-dimensional $(x, y, \lambda)$ dataset, called hyperspectral cube or "hypercube".

The hyperspectral device utilized in this study works in the NIR range (1000-1700 nm). The sensing unit is constituted by a Speclm's NIR spectral camera consisting of an ImSpector N17E imaging spectrograph, developed by Speclm ${ }^{\text {TM }}$ Oy, with a spectral sampling/pixel of $2.6 \mathrm{~nm}$ cou- pled with a temperature-stabilized InGaAs photodiode array $(320 \times 240$ pixels in image frame), positioned above a light source (Serranti and Bonifazi, 2010; DV Optics S.r.l., 2008). The illuminant system consists of a diffused light cylinder architecture, embedding five halogen bulbs. The equipment, connected to a PC, is mounted on a conveyor belt (width $=26 \mathrm{~cm}$ and length $=160 \mathrm{~cm}$ ) that can operate at variable speed (variable between $0 \mathrm{~mm} / \mathrm{s}$ and $50 \mathrm{~mm} / \mathrm{s}$ ).

The calibration of the spectrograph was performed by 
recording an image with the lens of the camera completely closed, dark image acquisition $\left(D_{i}\right)$, and by measuring the "white reference image" $\left(W_{i}\right)$ on a standardized white Spectralon ${ }^{\circledR}$ ceramic material. The dark reference was used to remove the effect of the CCD (charge-coupled device) dark current. After this calibration stage, the spectra image $\left(R_{0}\right)$ is acquired and the reflectance $\left(R_{i}\right)$ of the acquired image is then computed, by using the equation:

$R_{i}=\frac{R_{0_{i}}-D_{i}}{W_{i}-D_{i}}$

The calibration procedure was performed via Spectral Scanner $^{\text {TM }}$ v.2.3 software.

\subsubsection{Data acquisition}

Hyperspectral image acquisition was carried out setting the speed of the conveyor belt equal to $10 \mathrm{~mm} / \mathrm{s}$ (for 1000 frames). The 40 particles utilized to develop a model able for discriminating paper-based fragments from polymer-based particles (i.e. training set), were acquired in 6 hyperspectral images. To set-up the model to discriminate laminated card (i.e. Tetra Brik package fragments) from other cellulose materials, 5 laminated particles were acquired in 2 hyperspectral images from 2 sides: one image showing the plastic/paper/metal/plastic side (Side A) and the other image showing the plastic/metal/paper/plastic side (Side b) (Figure 4). To set up the model to identify laminated plastic fragments from other polymer-based particles, 6 laminated plastic fragments were acquired from
2 sides in 4 hyperspectral images: 2 images with the particles' plastic/metal side exposed (Side A) and 2 images with particles' metal/plastic side exposed (Side B) (Figure 5). The data set to validate the models was constituted by 16 particles included in "Validation set 1", scanned in 2 hyperspectral images, and 14 particles in "Validation set 2" also acquired in 2 hyperspectral images.

Acquired hyperspectral images ".sif" were converted into ".hdr" files and imported into MATLAB ${ }^{\circledR}$ environment (MATLAB R2018a ver. 9.4) as dataset objects. Imported datasets were thus analyzed using Eigenvector Research's PLS_toolbox (ver. 8.7) and MIA_toolbox (ver. 3.0) in MAT$\mathrm{LAB}^{\circledR}$ environment.

\subsubsection{Data pre-processing and explorative analysis}

The spectral range of each acquired hyperspectral image was firstly reduced from $950-1700 \mathrm{~nm}$ to $1000-1650$ $\mathrm{nm}$, excluding the noisiest parts of the spectra. Background removal was performed for all the hyperspectral images. Object silhouettes were cropped, and the background was excluded via the PLS_toolbox 'Image_Flatfield' function.

Regions of Interest (ROIs) were selected on the training set images and mean raw reflectance spectra were extracted. More in detail, 39 ROls were selected from the 6 hyperspectral images of the "Training set": 23 ROIs of polymer/ plastic-based particles and 16 ROls of paper-based particles ("Paper \& cardboard") as shown in Figure 6.

Spectra of the 39 ROls were thus extracted and con-
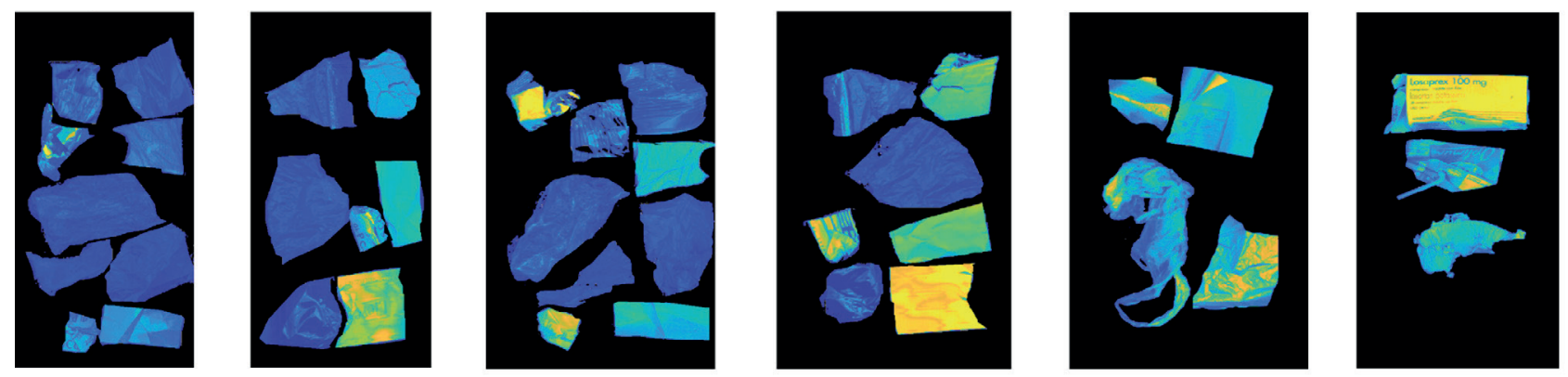

a
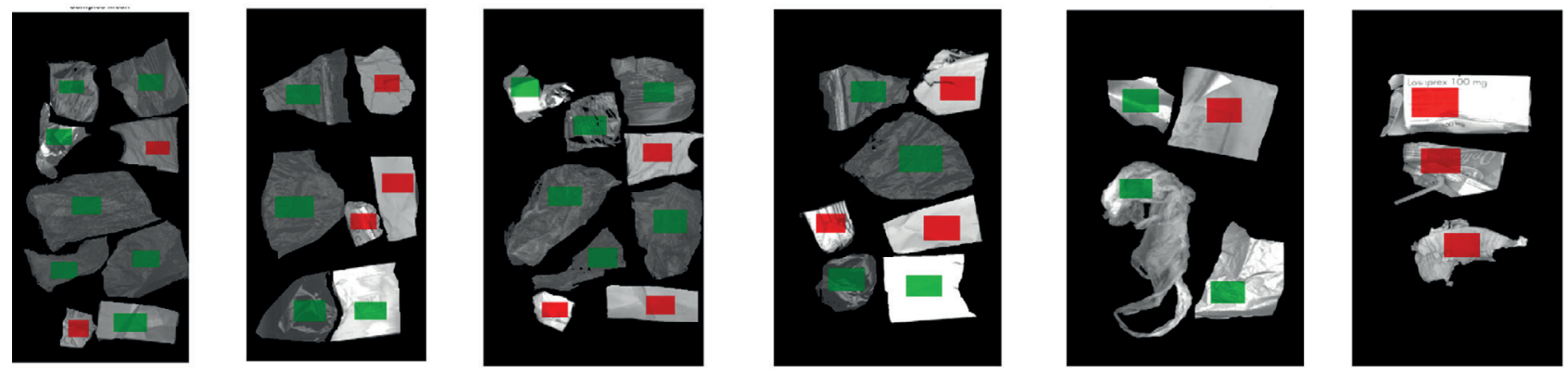

- Paper \& cardboard

Polymer

b

FIGURE 6: "Calibration set": hyperspectral images (a) and selected ROIs of "Paper \& cardboard" and "Polymer" (b). Red: Paper \& cardboard, green: Polymer. 
catenated to create a unique dataset (for the classes "Polymer" and "Paper \& cardboard"). The model calibration to discriminate laminated card (i.e. Tetra Brik package fragments) from other cellulose materials (Figure 7) was carried out by extracting 15 ROls from 2 acquired hyperspectral images (8 ROls from side $A$ and 7 ROls from side $B$ : side $A$ is the plastic/paper/metal/plastic side, while side $B$ is the plastic/metal/paper/plastic side). Spectra from extracted ROls were used to create a new dataset for class "Paper \& cardboard (laminated card)".

Figure 8 shows the 4 concatenated hyperspectral images depicting laminated plastic particles included in the calibration set and the extracted 30 ROls (14 ROIs on side $A$ and 16 ROls on side $B$ : side $A$ is the plastic/metal side, while side B is the metal/plastic). Spectra from extracted ROls were used to create a new dataset for class "Polymer (Laminated plastic)". While the hyperspectral images of the "Validation set 1 " were only concatenated together, as shown in Figure 9. The same procedure was applied to "Validation set 2".

A combination of pre-processing algorithms (Rinnan et al., 2009) was applied to spectral data used to train each step of the cascading classifier. Data pre-processing is not only necessary to implement both scattering corrections and noise removal procedures, but also to enhance differences occurring among clusters of data classes. Different pre-processing strategies were sequentially applied. The one giving the better response in terms of data decomposition

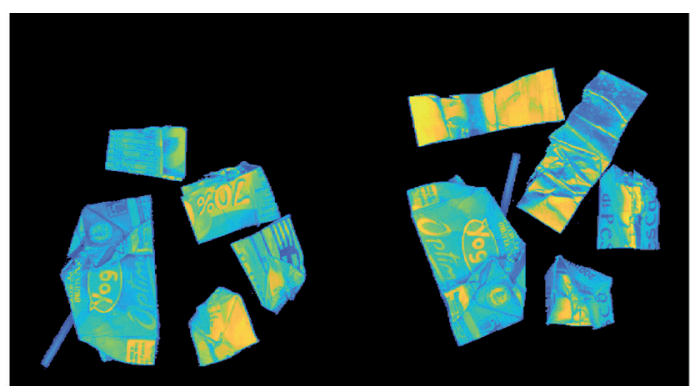

a

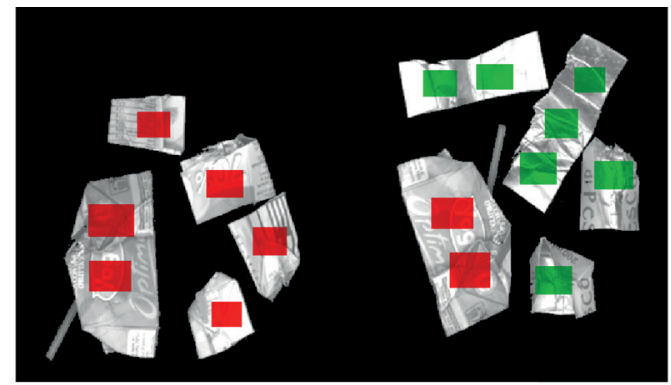

- Laminated card (A)

- Laminated card (B)

FIGURE 7: Laminated card particles (side A is the plastic/paper/metal/plastic side, while side B is the plastic/metal/paper/plastic side): a) concatenated hyperspectral images of the particles and b) ROIs selected on the hyperspectral images (Red: laminated card - side A, green: laminated card - side B).

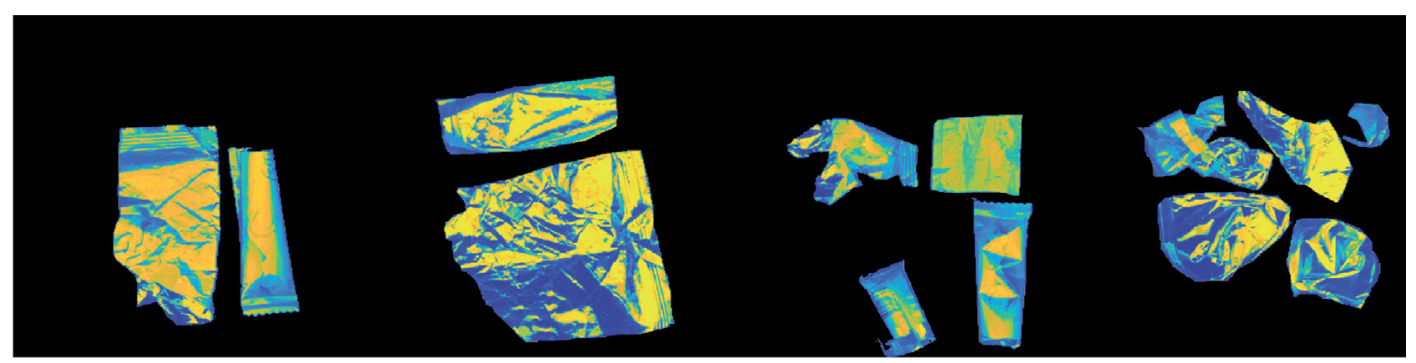

a

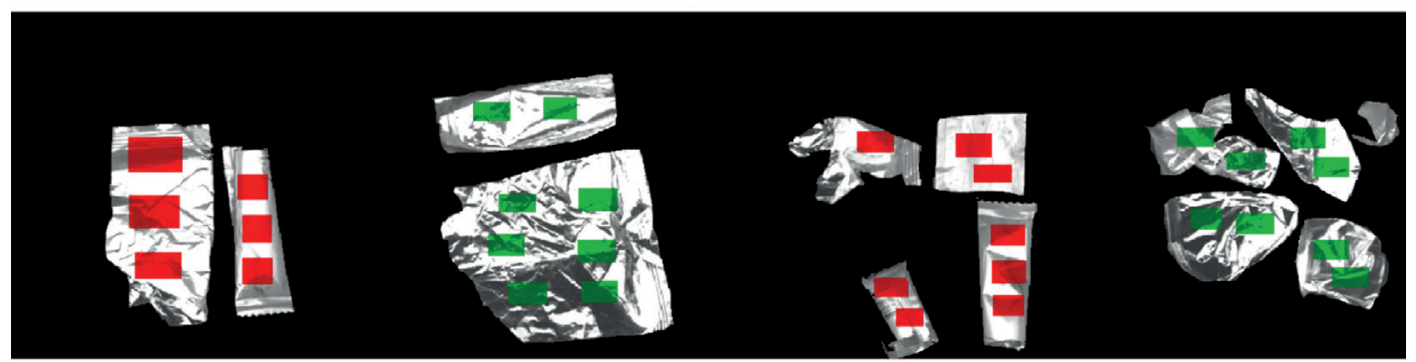

- Laminated plastic (A)

- Laminated plastic (B)

b

FIGURE 8: Laminated plastic particles (side A is the plastic/metal side, while side B is the metal/plastic): a) concatenated hyperspectral images of the particles and b) ROIs selected on the hyperspectral images (Red: laminated plastic - side A, green: laminated plastic - side B). 

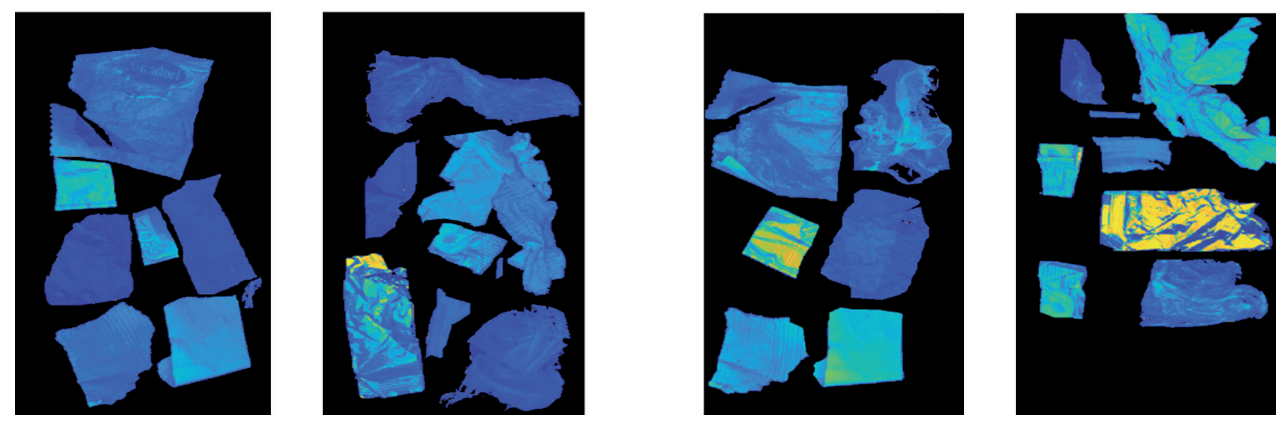

a

b

FIGURE 9: Hyperspectral images of "Validation set 1" (a) and "Validation set 2" (b)

was thus chosen, that is: Standard Normal Variate (SNV), Smoothing and Mean Center (MC) (Savitzky and Golay, 1964; Rinnan et al., 2009; Eigenvector, 2017; Eigenvector, 2018).

SNV consists of a scatter-corrective pre-processing method and it is one of the most widely used pre-processing techniques in NIR spectroscopy (Rinnan et al., 2009; Eigenvector, 2017). The smoothing algorithm is a low-pass filter used to remove high-frequency noise from samples. This pre-processing, based on the Savitzky-Golay algorithm, (Savitzky and Golay, 1964) is often used on spectra. Smoothing operates separately on each row of the spectra matrix acting on adjacent variables. Adjacent variables, containing similar information, are averaged together without significant loss of the spectral information. Finally, MC pre-process algorithm centers columns to have a zero mean (Eigenvector, 2018).

Principal Component Analysis (PCA), a well-known unsupervised pattern recognition technique, was chosen to perform the exploratory analysis of decomposed spectral data, according to sample type and for excluding outliers from the datasets (Wold et al. 1987; Rivsik, 2007; Wise et al., 2008).

\subsection{Cascade Model based on Partial Least Squares - Discriminant Analysis (PLS-DA)}

A two-step cascade model based on Partial Least Squares-Discriminant Analysis (PLS-DA) (Figure 1) was built and validated. PLS-DA is a supervised pattern recognition technique consisting of a multivariate inverse least squares discrimination method. Partial Least Squares (PLS) regression is used to develop a model able to predict the class of each sample (i.e. pixel) under study (Wise et al., 2008).

The first step of the cascade classification model was performed to identify cellulose-based fragments ("Paper \& cardboard") from polymer/plastic-based fragments ("Polymer"). The second step of the classification was performed in order to discriminate Laminated card ("Paper \& cardboard (Laminated card)") from the other cellulose-based particles ("Paper \& cardboard 2") and to identify laminated plastic fragments ("Polymer (Laminated plastic)") from other polymer-based fragments ("Polymer 2"). The first model was calibrated with the classes "Paper \& cardboard" and "Polymer" by using the spectra extracted from ROls selected on the calibration set (Figures 10a and 10b). Venetian-blinds, as a cross-validation method, were utilized to perform model tuning and to choose "the right grade of complexity" (Eigenvector, 2016): 3 Latent Variables (LVs) were used. The model was validated on "Validation set 1" and "Validation set 2", to assess the ability of new "unknown" sample prediction.

The second step of the cascading model was calibrated using:

i) the "Paper \& cardboard (Laminated card)" belonging to the selected ROIs, as shown in Figures $10 \mathrm{c}$ and $10 \mathrm{~d}$, to perform the discrimination between "Paper \& cardboard (Laminated card)" and "Paper \& cardboard 2" and

ii) the "Polymer (Laminated plastic)" belonging to the selected ROls, as shown in Figures 10c and 10d, to perform the discrimination between "Polymer (Laminated plastic)" and "Polymer 2".

In the first case, 5 LVs were used. The model was validated on "Validation set 1" and "Validation set 2", with the polymer-based particles removed from the analysis. In the second case, 5 Latent variables (LVs) were used. The model was validated on "Validation set 1" and "Validation set 2", with the cellulose-based particles removed from the analysis.

The confusion matrix, adopting a pixels-based logic, was considered to evaluate classifier performance in each of its steps and the commonly used performance metrics calculated from it. Sensitivity, Specificity, Precision, Accuracy, Misclassification Error and Class Error were calculated from the confusion matrix (Ballabio and Todeschini, 2009; Fawcett, 2006), which are:

$$
\begin{aligned}
& \text { Sensitivity }=\frac{T P}{T P+F N} \\
& \text { Specificity }=\frac{T N}{F P+T N}=1-\text { Sensitivity } \\
& \text { Precision }=\frac{T P}{T P+F P} \\
& \text { Accuracy }=1-\frac{T P+F N}{T P+T N+F P+F N}=\frac{T P+T N}{T P+T N+F P+F N}
\end{aligned}
$$

Misclassification Error $(E R R)=1-$ Accuracy

Class Error $=1-\left(\frac{\text { Sensitivity }+ \text { Specificity }}{2}\right)$

where: TP (True Positive) is a positive instance that is classified as positive; $F N$ (False Negative) is a positive instance 


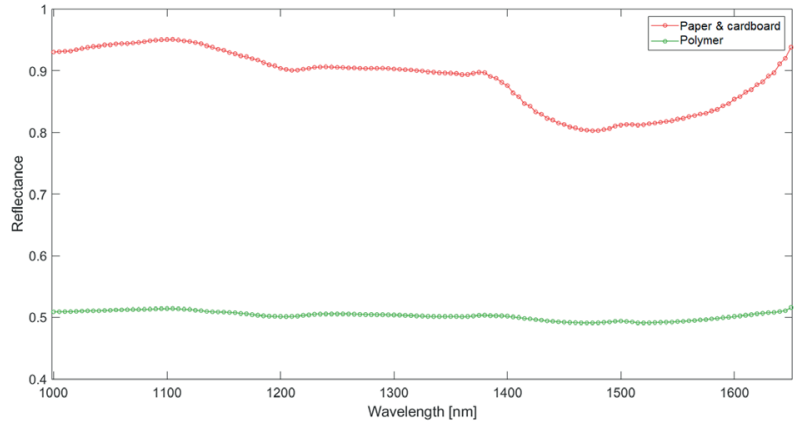

a

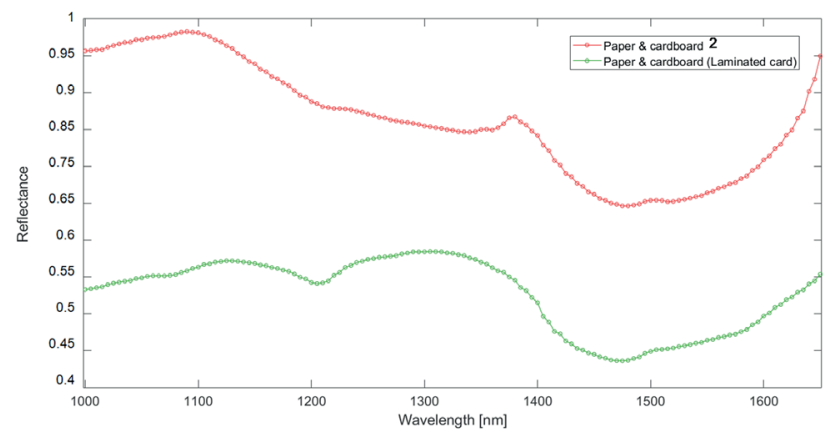

C

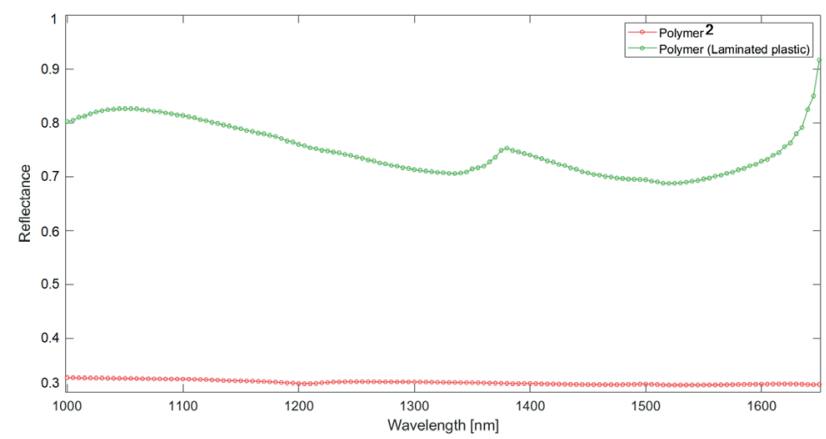

e

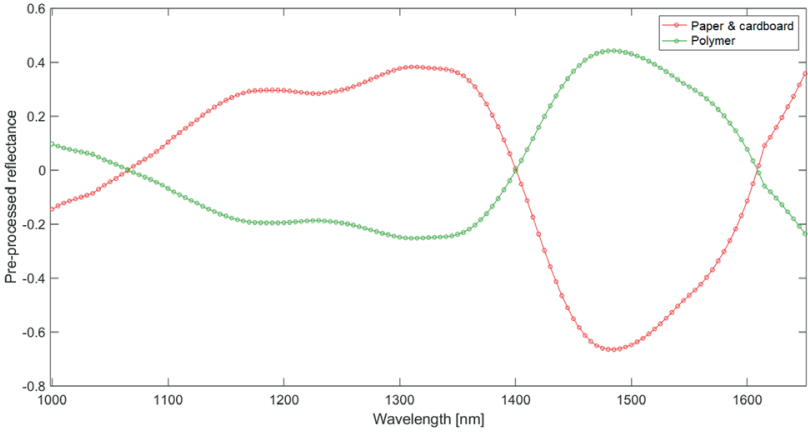

b

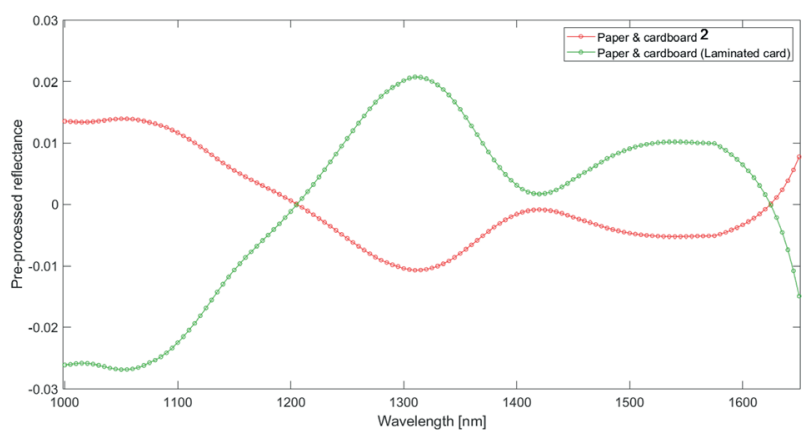

d

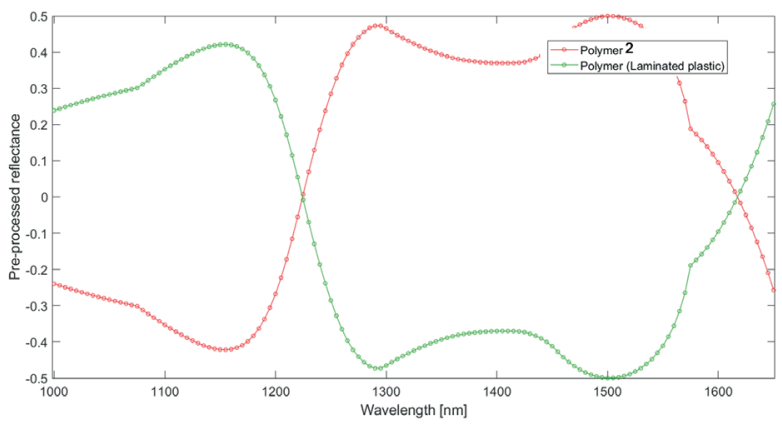

$\mathbf{f}$

FIGURE 10: "Paper \& cardboard" - "Polymer" calibration set: grand-average of raw reflectance spectra (a) and pre-processed spectra (b). "Paper \& cardboard 2" and "Paper \& cardboard (Laminated card)" calibration set: grand-average of raw reflectance spectra (c) and pre-processed spectra (d). "Polymer 2" and "Polymer (Laminated plastic)": grand-average of raw reflectance spectra (e) and pre-processed spectra (f).

that is classified as negative; $T N$ (True Negative) is a negative instance that is a classified as negative and FP (False Positive) is a negative instance that is classified as positive.

While, in an object-based logic, considering $50 \%$ of the pixels in each object as discriminating threshold, the overall performance of the cascade model was computed in terms of Recognition (i.e. Accuracy), Error and Reliability rates, according to Eq. 9, Eq. 10 and Eq. 11 (Silva et Al. 2017).

Recognition $=\frac{N_{\text {Cor }}}{N}$

Error $=\frac{N_{M i s}}{N}$

Reliability $=\frac{N_{\text {Cor }}}{N_{M i s}+N_{c o r}}$

being $N$ the total number of samples, while $N_{\text {cor }}$ and $N_{\text {Mis }}$ are the total of well-recognized and misrecognized samples, respectively.

\section{RESULTS AND DISCUSSION}

\subsection{Cascade classification model}

\subsection{1 "Paper \& cardboard" - "Polymer" model}

"Paper \& cardboard" - "Polymer" Classification model performance details for Calibration, Cross-validation and Validation phases are reported in Table 1. As can be seen in Figure 11, the validated model was able to recognize all the particles in "Validation set 1" and 13 out of 14 particles in "Validation set 2" (93\% of the total in the set: a "Polymer" plastic (i.e. a laminated plastic fragment circled in blue) was misclassified for over $50 \%$ of pixels as "Paper \& cardboard". 
TABLE 1: "Paper \& cardboard" - "Polymer" classification model details for Calibration, Cross-validation and Validation phases: Sensitivity, Specificity, Misclassification Error, Precision, accuracy and Class Error.

\begin{tabular}{|c|c|c|c|c|c|c|c|}
\hline & Class & Sensitivity & Specificity & $\begin{array}{c}\text { Misclassification } \\
\text { Error }\end{array}$ & Precision & Accuracy & Class Error \\
\hline \multirow{2}{*}{ Calibration } & Paper \& cardboard & 1.000 & 0.970 & 0.021 & 0.938 & 0.980 & 0.015 \\
\hline & Polymer & 0.970 & 1.000 & 0.021 & 1.000 & 0.980 & 0.015 \\
\hline \multirow{2}{*}{ Cross-validation } & Paper \& cardboard & 1.000 & 0.970 & 0.021 & 0.938 & 0.980 & 0.015 \\
\hline & Polymer & 0.970 & 1.000 & 0.021 & 1.000 & 0.980 & 0.015 \\
\hline \multirow{2}{*}{ Validation set 1} & Paper \& cardboard & 0.952 & 0.993 & 0.020 & 0.985 & 0.980 & 0.028 \\
\hline & Polymer & 0.993 & 0.952 & 0.020 & 0.978 & 0.980 & 0.028 \\
\hline \multirow{2}{*}{ Validation set 2} & Paper \& cardboard & 0.958 & 0.896 & 0.083 & 0.829 & 0.917 & 0.073 \\
\hline & Polymer & 0.896 & 0.958 & 0.083 & 0.976 & 0.917 & 0.073 \\
\hline
\end{tabular}
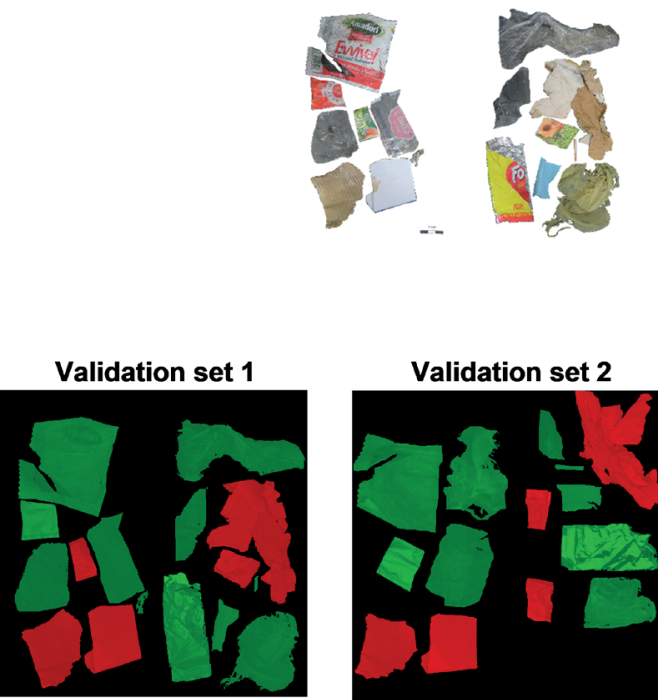

Paper \& cardboard

Polymer
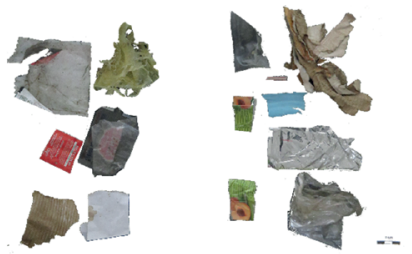

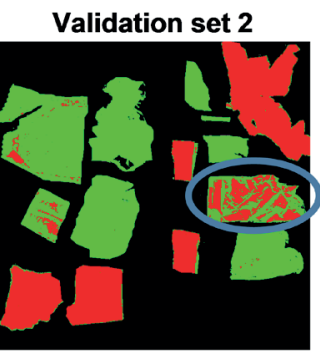

Predicted as "Paper \& carboard"

Predicted as "Polymer"

a

b

FIGURE 11: The validation set 1 and set 2 - "Paper \& cardboard" and "Polymer" classification: actual classes (a) and classes predicted by the PLS-DA model. By comparing the actual classes to the prediction map, it can be seen that all the fragments were correctly classified by the two-class PLS-DA model in "Validation set 1". While, In "validation set 2", a comparison between the actual classes and the PLS-DA prediction map highlights the misclassification of a particle (circled in blue), a laminated plastic fragment, predicted for more than $50 \%$ of the pixels as "Paper \& cardboard".

3.1.2 "Paper \& cardboard 2" - "Paper \& cardboard (Laminated card)" model

"Paper \& cardboard 2" - "Paper \& cardboard (Laminated card)" achieved good classification model performance as reported in Table 2. As can be seen in Figure 12, the validated model was able to recognize all the particles in "Validation set 1" and in "Validation set 2".

\subsection{3 "Polymer 2" - "Polymer (Laminated plastic)" model}

"Polymer 2" - "Polymer (Laminated plastic)" classification model performance details for calibration, cross-validation and validation phases are reported in Table 3 . The validated model was able to recognize 10/11 particles in "Validation set 1" (91\% of the total in the set, as can be seen in Figure 13): a "Polymer (Laminated plastic)" fragment (i.e. a laminated plastic fragment circled in blue, as seen in Figure 13), was misclassified for over $50 \%$ of pixels as "Polymer 2" class. However, the model can predict all particle class labels in "Validation set 2".

\subsubsection{Overall performances of the cascade identification process}

The "Paper \& cardboard" - "Polymer" classification model can discriminate 29 out of 30 particles (97\% total particles of the two validation sets), reaching a Recognition and a Reliability of 0.967. In the second step of the cascade classification, the "Paper \& cardboard 2" - "Paper \& cardboard (Laminated card)" model is able to discriminate all 
TABLE 2: "Paper \& cardboard 2" - "Paper \& cardboard (Laminated card)" classification model details for Calibration, Cross-validation and Validation phases: Sensitivity, Specificity, Misclassification Error, Precision, accuracy and Class Error.

\begin{tabular}{|c|c|c|c|c|c|c|c|}
\hline & Class & Sensitivity & Specificity & $\begin{array}{l}\text { Misclassification } \\
\text { Error }\end{array}$ & Precision & Accuracy & Class Error \\
\hline \multirow{2}{*}{ Calibration } & $\begin{array}{c}\text { Paper \& } \\
\text { cardboard } 2\end{array}$ & 0.882 & 0.937 & 0.099 & 0.965 & 0.901 & 0.090 \\
\hline & $\begin{array}{l}\text { Paper \& cardboard } \\
\text { (Laminated card) }\end{array}$ & 0.937 & 0.882 & 0.099 & 0.804 & 0.901 & 0.090 \\
\hline \multirow{2}{*}{ Cross-validation } & $\begin{array}{c}\text { Paper \& } \\
\text { cardboard } 2\end{array}$ & 0.881 & 0.937 & 0.100 & 0.965 & 0.901 & 0.091 \\
\hline & $\begin{array}{l}\text { Paper \& cardboard } \\
\text { (Laminated card) }\end{array}$ & 0.937 & 0.881 & 0.100 & 0.804 & 0.901 & 0.091 \\
\hline \multirow{2}{*}{ Validation set 1} & $\begin{array}{c}\text { Paper \& } \\
\text { cardboard } 2\end{array}$ & 0.983 & 0.887 & 0.031 & 0.982 & 0.969 & 0.065 \\
\hline & $\begin{array}{l}\text { Paper \& cardboard } \\
\text { (Laminated card) }\end{array}$ & 0.887 & 0.983 & 0.031 & 0.894 & 0.969 & 0.065 \\
\hline \multirow{2}{*}{ Validation set 2} & $\begin{array}{c}\text { Paper \& } \\
\text { cardboard } 2\end{array}$ & 0.997 & 0.954 & 0.009 & 0.992 & 0.991 & 0.024 \\
\hline & $\begin{array}{l}\text { Paper \& cardboard } \\
\text { (Laminated card) }\end{array}$ & 0.954 & 0.997 & 0.009 & 0.983 & 0.991 & 0.024 \\
\hline
\end{tabular}
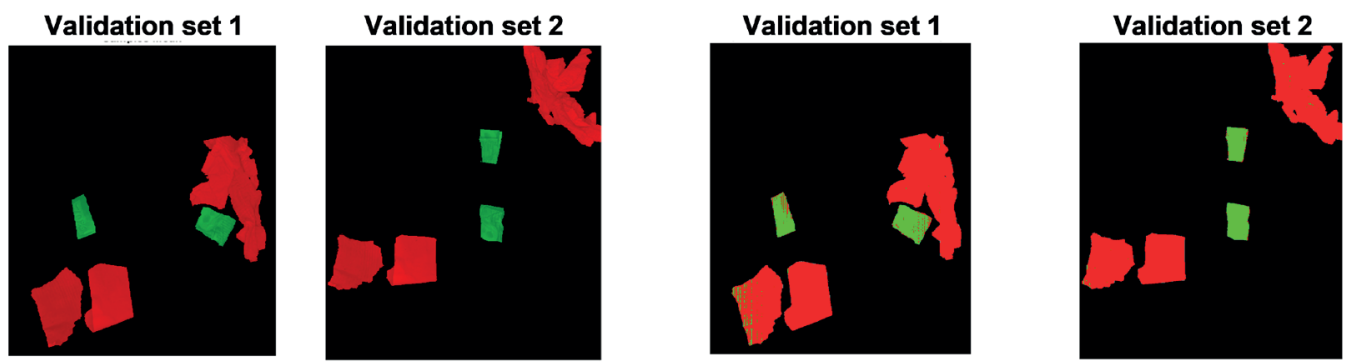

Paper \& cardboard 2

Predicted as "Paper \& carboard 2"

Paper \& cardboard (Laminated card)

Predicted as "Paper \& cardboard (Laminated card)"

a

b

FIGURE 11: The validation set 1 and set 2 - "Paper \& cardboard 2" - "Paper \& cardboard (Laminated card)" classification: actual classes (a) and classes predicted by the PLS-DA model. Fragments were correctly classified by the two-class PLS-DA model as comparing the actual classes to the prediction map.

the particles included into the two validation sets (10 out of 10 ), thus reaching a Recognition and a Reliability of 1 . While "Polymer 2" - "Polymer (Laminated plastic)" model is able to correctly classify 19 out of 20 of the particles included in the validation sets, reaching a Recognition and a Reliability of 0.950 . The misclassified fragments are laminated plastics, this misclassification is due to their high reflection related to the exposed surfaces wrinkling of the bent packaging fragments and linked to scattering phenomena.

Following a pixel-based logic, the most reflective zones and shadow zones of the bent fragments are sometimes misclassified. To sum up, the cascade model, by having misclassified 2 out of 30 particles in total, reached in prediction a Recognition and a Reliability of 0.933 , with an Error equal to 0.066 .

\section{CONCLUSIONS}

A PLS-DA-based cascading classification model able to recognize polymeric fragments from cellulosic ones and to identify multi-layer materials (i.e. laminated plastic and lam- inated cardboard) was built and validated. In the first step of the cascade classification model, finalized to discriminate cellulose-based from polymer/plastic-based fragments 29 out of 30 objects were recognized. In the second step, the laminated card and other cellulose-based particles were all correctly recognized and only one fragment of laminated plastic was misclassified performing discrimination of laminated plastic fragments from other polymer/plastic-based fragments. The set up cascade model reached in prediction an overall Recognition and Reliability of 0.933 .

A NIR-HSI-based approach can represent an optimal, reliable and low-cost answer to systematically identify impurities and composite materials inside plastic waste streams. The proposed approach, if fully implemented, can be utilized as a control strategy for continuous monitoring or as an analytical core for sorting materials in post-consumer plastic packaging waste characterized by the presence of paper, cardboard and multilayer packaging.

Results showed as the application of hyperspectral imaging, in the near-infrared range (1000-1700 nm), applied 
TABLE 3: The "Polymer 2" - "Polymer (Laminated plastic)" classification model details for Calibration, Cross-validation and Validation phases: Sensitivity, Specificity, Misclassification Error, Precision, accuracy and Class Error.

\begin{tabular}{|c|c|c|c|c|c|c|c|}
\hline & Class & Sensitivity & Specificity & $\begin{array}{c}\text { Misclassification } \\
\text { Error }\end{array}$ & Precision & Accuracy & Class Error \\
\hline \multirow{2}{*}{ Calibration } & Polymer 2 & 0.930 & 0.839 & 0.107 & 0.894 & 0.893 & 0.116 \\
\hline & $\begin{array}{c}\text { Polymer } \\
\text { (Laminated plastic) }\end{array}$ & 0.839 & 0.930 & 0.107 & 0.891 & 0.893 & 0.116 \\
\hline \multirow[b]{2}{*}{ Cross-validation } & Polymer 2 & 0.930 & 0.839 & 0.107 & 0.894 & 0.893 & 0.116 \\
\hline & $\begin{array}{c}\text { Polymer } \\
\text { (Laminated plastic) }\end{array}$ & 0.839 & 0.930 & 0.107 & 0.891 & 0.893 & 0.116 \\
\hline \multirow[b]{2}{*}{ Validation set 1} & Polymer 2 & 1.000 & 0.304 & 0.130 & 0.863 & 0.870 & 0.348 \\
\hline & $\begin{array}{c}\text { Polymer } \\
\text { (Laminated plastic) }\end{array}$ & 0.304 & 1.000 & 0.130 & 0.998 & 0.870 & 0.348 \\
\hline \multirow[b]{2}{*}{ Validation set 2} & Polymer 2 & 0.990 & 0.621 & 0.093 & 0.900 & 0.907 & 0.194 \\
\hline & $\begin{array}{c}\text { Polymer } \\
\text { (Laminated plastic) }\end{array}$ & 0.621 & 0.990 & 0.093 & 0.948 & 0.907 & 0.194 \\
\hline
\end{tabular}

Validation set 1

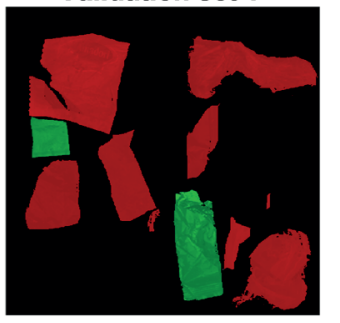

Polymer 2

Polymer (Laminated plastic)

a
Validation set 2

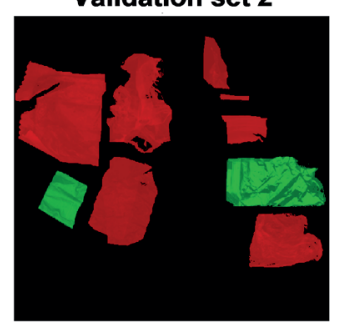

(1)

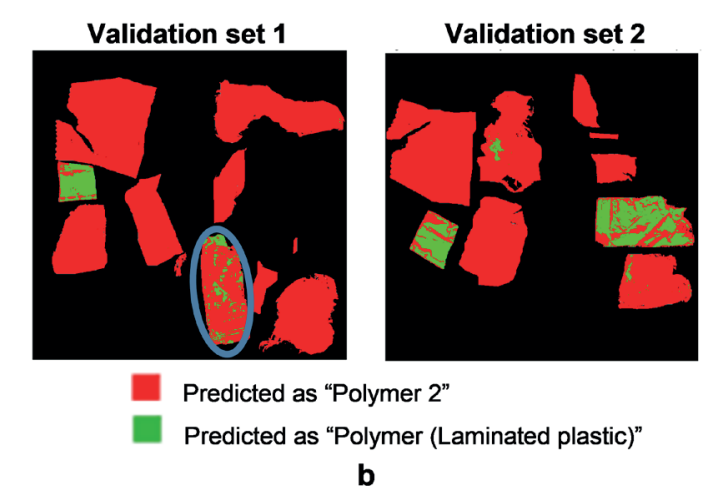

FIGURE 13: The validation set 1 and set 2 - "Polymer 2" - "Polymer (Laminated plastic)" classification: actual classes (a) and classes predicted by the PLS-DA model. In Validation set 1, a comparison between the actual classes and the PLS-DA prediction map highlights the misclassification of a particle (circled in blue), a laminated plastic fragment, predicted for more than $50 \%$ of the pixels as "Polymer 2 ". While in Validation set 2, all the fragments were correctly classified by the two-class PLS-DA model; however, some pixels are misclassified.

on a packaging waste stream, opens the door to future innovations in the field of resources and recycling, that is the possibility to develop sensing architectures to recognize plastic and/or 2D pollutants (i.e paper-based packaging and laminated card fragments), in order to be used not only as a sorting engine but also as an analytical core to perform quality control on products and/or byproducts coming from different manufacturing stages.

\section{REFERENCES}

Agresti G, Bonifazi G., Calienno L., Capobianco G., Lo Monaco A., Pelosi C., Picchio R. and Serranti, S., 2013. Surface Investigation of Photo-Degraded Wood by Colour Monitoring, Infrared Spectroscopy, and Hyperspectral Imaging. Journal of Spectroscopy, 380536, 2314-4920. https://doi.org/10.1155/2013/380536.

Ballabio D., and Todeschini R., 2009. Multivariate Classification for Qualitative Analysis. In S. Da-Wen, Infrared Spectroscopy for Food Quality Analysis and Control, 83-104.

Bonifazi G., Palmieri R., Serranti S., 2015a, Short wave infrared hyperspectral imaging for recovered postconsumer single and mixed polymers characterization. Image Sensors and Imaging Systems 2015, Proc. of SPIE-IS\&T Electronic Imaging, SPIE Vol. 9403, 94030R. https://doi.org/10.1117/12.2081362.

Bonifazi G., Palmieri R. and Serranti S., 2015b. Hyperspectral imaging applied to end-of-life (EOL) concrete recycling, tm-Technisches Messen, 82 (12), 616-624.
Bonifazi G., Serranti S., Bonoli A. and Dall'Ara A., 2009. Innovative recognition-sorting procedures applied to solid waste: the hyperspectral approach, Sustainable Development and Planning IV, 2, 885-889.

Capobianco G., Prestileo F., Serranti S. and Bonifazi G., 2015, Hyperspectral imaging-based approach for the in-situ characterization of ancient Roman wall paintings, Periodico di Mineralogia, 3A (Special issue), 407-418.

DV Optics S.r.l. 2008. Spectral Scanner Operative Manual (Version 2.0). Italy. Available at: http://www.dvoptic.com/index.html (Accessed: 5 March 2021).

Eigenvector, 2016. Using Cross-Validation. Available at: http://wiki. eigenvector.com/index.php?title=Using_Cross-Validation (Accessed: 5 March 2021).

Eigenvector, 2017. Advanced Preprocessing: Sample Normalization. Available at: http://wiki.eigenvector.com/index.php?title=Advanced_Preprocessing:_Sample_Normalization (Accessed: 5 March 2021).

Eigenvector, 2018. Preprocess. Available at: http://www.wiki.eigenvector.com/index.php?title=Preprocess (Accessed: 5 March 2021).

Fawcett T., 2006). An introduction to ROC analysis. Pattern Recognition Letters, 27 (8), 861-874.

Hollstein F., Wohllebe M., Arnaiz S., 2015. Identification and Sorting of Plastics Film Waste by NIR-Hyperspectral-Imaging. near infrared spectroscopy: proceedings of the international conference, 2015, Foz do Iguaçu, Brazil.

Hu B., Serranti S., Fraunolcz N., Di Maio F. and Bonifazi G., 2013. Recycling-oriented characterization of polyolefin packaging waste. Waste Management, 33 (3), 574-584. https://doi.org/10.1016/j. wasman.2012.11.018. 
Jansen M., Thoden van Velzen E.U. and Pretz Th., 2015. Handbook for sorting of plastic packaging waste concentrates: separation efficiencies of common plastic packaging objects in widely used separation machines at existing sorting facilities with mixed postconsumer plastic packaging waste as input. (Reports of Wageningen UR Food \& Biobased Research; No. 1604) Wageningen UR Food \& Biobased Research, Wageningen, Netherlands.

Kumaravelu C., and Gopal A., 2015. A Review on the applications of Near-Infrared Spectrometer and Chemometrics for the Agro-Food Processing Industries. 2015 IEEE Technological Innovation in ICT for Agriculture and Rural Development (TIAR), Chennai, India, 8-12. doi: 10.1109/TIAR.2015.7358523.

Larrechi M.S., and Callao M.P., 2003. Strategy for introducing NIR spectroscopy and multivariate calibration techniques in industry. Trends in Analytical Chemistry, 22 (9), 634-640. https://doi. org/10.1016/S0165-9936(03)01005-7.

Palmieri R., Bonifazi G., Serranti S., 2014. Recycling-oriented characterization of plastic frames and printed circuit boards from mobile phones by electronic and chemical imaging, Waste Management, 34 (11), 2120-2130. https://doi.org/10.1016/j.wasman.2014.06.003.

Pasquini C., 2003. Near Infrared Spectroscopy: Fundamentals, Practical Aspects and Analytical Applications, Journal of the Brazilian Chemical Society, 14 (2), 198-219. https://doi.org/10.1590/S010350532003000200006.

Rinnan $\AA$., van den Berg F. and Engelsen S.B., 2009. Review of the most common pre-processing techniques for near-infrared spectra, TrAC Trends in Analytical Chemestry, 28 (10), 1201-1222. https:// doi.org/10.1016/j.trac.2009.07.007.

Risvik, H., 2007. Principal Component Analysis (PCA) \& NIPALS algorithm. Available at: http://neuroinformatics.be/wp-content/uploads/2016/01/pca_nipals.pdf (Accessed: 5 March 2021).

Roggo Y., Chalus P., Maurer L., Lema-Martinez C., Edmond A. and Jent N., 2007. A review of near infrared spectroscopy and chemometrics in pharmaceutical technologies, Journal of Pharmaceutical and Biomedical Analysis, 44 (3), 683-700. https://doi. org/10.1016/j.jpba.2007.03.023.

Savitzky, A. and Golay, M.J.E., 1964. Smoothing and Differentiation of Data by Simplified Least-Squares Procedures. Analytical Chemistry, 36 (8), 1627-1639. https://doi.org/10.1021/ac60214a047.

Serranti S. and Bonifazi G., 2010. Post-Consumer Polyolefins (PP-PE) Recognition by Combined Spectroscopic Sensing Techniques, The Open Waste Management Journal, 3, 35-45.
Serranti S., Bonifazi G., Gasbarrone R., 2018a. Kiwifruits ripening assessment by portable hyperspectral devices. Proc. SPIE 10665 Sensing for Agriculture and Food Quality and Safety X, Orlando, Florida, United States, 106650S.

Serranti S., Bonifazi G., Gasbarrone R., 2018b, Olive fruit ripening evaluation and quality assessment by hyperspectral sensing devices. Proc. SPIE 10665, Sensing for Agriculture and Food Quality and Safety X, Orlando, Florida, United States, 106650R.

Serranti S., Gargiulo A., and Bonifazi G., 2011. Characterization of post-consumer polyolefin wastes by hyperspectral imaging for quality control in recycling processes. Waste Management, 31 (11), 2217-2227. https://doi.org/10.1016/j.wasman.2011.06.007.

Serranti S., Palmieri R., Bonifazi G., 2013. Opto-electronic combined characterization of end-of-life mobile phone wastes for a sustainable processing. Proceedings Sardinia 2013, Fourteenth International Waste Management and Landfill Symposium, S. Margherita di Pula, Cagliari, Italy.

Serranti S., Palmieri R., Bonifazi G., 2015. Hyperspectral imaging applied to demolition waste recycling: an innovative approach for quality control, Journal of Electronic Imaging, 24 (4), 0430031_043003-9. https://doi.org/10.1117/1.JEl.24.4.043003.

Silva E. J., Britto A. S., Oliveira L. S., Enembreck F., Sabourin R. and Koerich A. L., 2017. A two-step cascade classification method, 2017 International Joint Conference on Neural Networks (IJCNN), Anchorage, Alaska, United States, 573-580.

Tsuchikawa S. and Kobori H., 2015. A review of recent application of near infrared spectroscopy to wood science and technology, Journal of Wood Science, 61, 213-220. https://doi.org/10.1007/ s10086-015-1467-x

Ulrici A., Serranti S., Ferrari C., Cesare D., Foca G. and Bonifazi G., 2013. Efficient chemometric strategies for PET-PLA discrimination in recycling plants using hyperspectral imaging, Chemometrics and Intelligent laboratory Systems, 122, 31-39. https://doi.org/10.1016/j. chemolab.2013.01.001.

Wise B. M., Gallagher N. B., Bro R., Shaver J. M., Windig W., Koch R.S., 2008. PLS_Toolbox 4.2 Reference Manual for use with MATLAB ${ }^{\mathrm{TM}}$, Eigenvector Research Incorporated Inc, Wenatchee, Washington, United States.

Wold, S., Esbensen, K. and Geladi, P., 1987. Principal Component Analysis, Chemometrics and Intelligent Laboratory Systems, 2, 37-52. https://doi.org/10.1016/0169-7439(87)80084-9.

Yamane, T., 1967. Statistics: An Introductory Analysis, 2nd edition, Harper and Row, New York, United States.

\section{APPENDIX}

The detailed information regarding the sample sets selected to perform model calibration and validation are reported in Figure A1. Each fragment is labeled and their characteristics, for the different sets, are reported in Table A1.
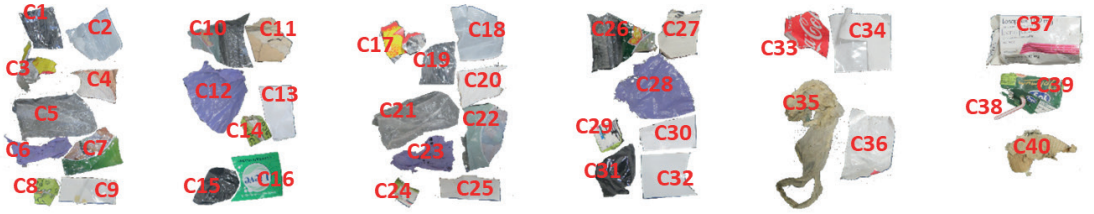

Calibration se

(Paper, cardboard and plastic)
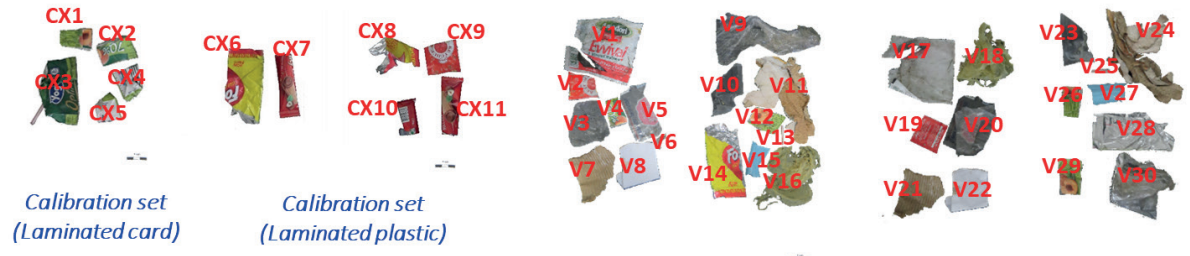

Validation set 1

Validation set 2

FIGURE A1: Reference image of the sample sets. For each fragment is reported the sample identification label. 
TABLE A1: Characteristics of the sample sets used in this study.

\begin{tabular}{|c|c|c|c|c|}
\hline Sample set & Sample ID & Fragment/sample definition & Sample class & Lamination \\
\hline \multirow{40}{*}{$\begin{array}{l}\text { Calibration set } \\
\text { (Paper, cardboard } \\
\text { and plastic) }\end{array}$} & $\mathrm{C} 1$ & Transparent plastic cup & Plastic & \\
\hline & $\mathrm{C} 2$ & White plastic cup & Plastic & \\
\hline & $\mathrm{C} 3$ & Laminated plastic potato chip bag & Plastic & Laminated plastic \\
\hline & $\mathrm{C} 4$ & Pizza cardboard carton & Paper and cardboard & \\
\hline & C5 & Transparent plastic film & Plastic & \\
\hline & C6 & Plastic bag & Plastic & \\
\hline & $\mathrm{C7}$ & Plastic peanut bag & Plastic & \\
\hline & $\mathrm{C} 8$ & Tetra Brik juice carton & Paper and cardboard & Laminated cardboard \\
\hline & $\mathrm{Cg}$ & Laminated paper envelope & Paper and cardboard & Laminated card \\
\hline & C10 & Plastic peanut bag & Plastic & \\
\hline & $\mathrm{C} 11$ & Cardboard carton & Paper and cardboard & \\
\hline & $\mathrm{C} 12$ & Plastic bag & Plastic & \\
\hline & C13 & Paper & Paper and cardboard & \\
\hline & $\mathrm{C} 14$ & Tetra Brik juice carton & Paper and cardboard & Laminated cardboard \\
\hline & C15 & Transparent plastic bottle & Plastic & \\
\hline & $\mathrm{C} 16$ & Plastic bottle label & Plastic & \\
\hline & $\mathrm{C} 17$ & Laminated plastic potato chip bag & Plastic & Laminated plastic \\
\hline & C18 & White plastic cup & Plastic & \\
\hline & C19 & Transparent plastic cup & Plastic & \\
\hline & $\mathrm{C} 20$ & Cardboard carton & Paper and cardboard & \\
\hline & $\mathrm{C} 21$ & Transparent plastic film & Plastic & \\
\hline & $\mathrm{C} 22$ & Plastic peanut bag & Plastic & Laminated plastic \\
\hline & $\mathrm{C} 23$ & Plastic bag & Plastic & \\
\hline & $\mathrm{C} 24$ & Tetra Brik juice carton & Paper and cardboard & Laminated cardboard \\
\hline & $\mathrm{C} 25$ & Laminated paper envelope & Paper and cardboard & Laminated card \\
\hline & $\mathrm{C} 26$ & Plastic peanuts bag & Plastic & \\
\hline & $\mathrm{C} 27$ & Cardboard carton & Paper and cardboard & \\
\hline & $\mathrm{C} 28$ & Plastic bag & Plastic & \\
\hline & $\mathrm{C} 29$ & Tetra Brik juice carton & Paper and cardboard & \\
\hline & $\mathrm{C} 30$ & Paper & Paper and cardboard & \\
\hline & $\mathrm{C} 31$ & Transparent plastic bottle & Plastic & \\
\hline & $\mathrm{C} 32$ & Plastic bottle label & Plastic & \\
\hline & $\mathrm{C} 33$ & Plastic bottle label & Plastic & \\
\hline & $\mathrm{C} 34$ & Laminated paper - plastic envelope & Paper and cardboard & Laminated card \\
\hline & $\mathrm{C} 35$ & Plastic bag & Plastic & \\
\hline & $\mathrm{C} 36$ & Plastic bottle label & Plastic & \\
\hline & $\mathrm{C} 37$ & Paper box & Paper and cardboard & \\
\hline & $\mathrm{C} 38$ & Tetra Brik juice carton & Paper and cardboard & Laminated cardboard \\
\hline & C39 & Plastic straw & Plastic & \\
\hline & $\mathrm{C} 40$ & Cardboard carton & Paper and cardboard & \\
\hline \multirow{5}{*}{$\begin{array}{l}\text { Calibration set } \\
\text { (Laminated card) }\end{array}$} & $\mathrm{cX} 1$ & Tetra Brik juice carton & Paper and cardboard & Laminated cardboard \\
\hline & $\mathrm{cX} 2$ & Tetra Brik juice carton & Paper and cardboard & Laminated cardboard \\
\hline & $\mathrm{CX} 3$ & Tetra Brik juice carton & Paper and cardboard & Laminated cardboard \\
\hline & $\mathrm{CX} 4$ & Tetra Brik juice carton & Paper and cardboard & Laminated cardboard \\
\hline & CX5 & Tetra Brik juice carton & Paper and cardboard & Laminated cardboard \\
\hline
\end{tabular}




\begin{tabular}{|c|c|c|c|c|}
\hline \multirow{6}{*}{$\begin{array}{l}\text { Calibration set } \\
\text { (Laminated } \\
\text { plastic) }\end{array}$} & CX6 & Laminated plastic potato chip bag & Plastic & Laminated plastic \\
\hline & $\mathrm{CX7}$ & Laminated plastic snack bag & Plastic & Laminated plastic \\
\hline & $\mathrm{cX8}$ & Laminated plastic potato chip bag & Plastic & Laminated plastic \\
\hline & $\mathrm{CX9}$ & Laminated plastic ketchup sachet & Plastic & Laminated plastic \\
\hline & CX10 & Laminated plastic snack bag & Plastic & Laminated plastic \\
\hline & CX11 & Laminated plastic snack bag & Plastic & Laminated plastic \\
\hline \multirow[t]{16}{*}{ Validation set 1} & $\mathrm{~V} 1$ & Sausage plastic bag & Plastic & \\
\hline & V2 & Laminated plastic ketchup sachet & Plastic & Laminated plastic \\
\hline & V3 & Transparent plastic film & Plastic & \\
\hline & V4 & Tetra Brik juice carton & Paper and cardboard & Laminated cardboard \\
\hline & V5 & Plastic bottle label & Plastic & \\
\hline & V6 & Plastic bag & Plastic & \\
\hline & V7 & Cardboard carton & Paper and cardboard & \\
\hline & V8 & Paper & Paper and cardboard & \\
\hline & V9 & Transparent plastic film & Plastic & \\
\hline & V10 & Transparent plastic bag & Plastic & \\
\hline & V11 & Cardboard carton & Paper and cardboard & \\
\hline & $\mathrm{V} 12$ & Tetra Brik juice carton & Paper and cardboard & Laminated cardboard \\
\hline & V13 & Plastic straw & Plastic & \\
\hline & V14 & Laminated plastic potato chip bag & Plastic & Laminated plastic \\
\hline & V15 & Plastic plate & Plastic & \\
\hline & V16 & Plastic bag & Plastic & \\
\hline \multirow[t]{14}{*}{ Validation set 2} & V17 & Sausage plastic bag & Plastic & \\
\hline & V18 & Plastic bag & Plastic & \\
\hline & V19 & Laminated plastic ketchup sachet & Plastic & Laminated plastic \\
\hline & $\mathrm{V} 20$ & Plastic bottle label & Plastic & \\
\hline & $\mathrm{V} 21$ & Cardboard carton & Paper and cardboard & \\
\hline & V22 & Paper & Paper and cardboard & \\
\hline & V23 & Transparent plastic bag & Plastic & \\
\hline & V24 & Cardboard carton & Paper and cardboard & \\
\hline & $\mathrm{V} 25$ & Plastic straw & Plastic & \\
\hline & $\mathrm{V} 26$ & Tetra Brik juice carton & Paper and cardboard & Laminated cardboard \\
\hline & V27 & Plastic plate & Plastic & \\
\hline & V28 & Laminated plastic potato chip bag & Plastic & Laminated plastic \\
\hline & $\mathrm{V} 29$ & Tetra Brik juice carton & Paper and cardboard & Laminated cardboard \\
\hline & V30 & Transparent plastic film & Plastic & \\
\hline
\end{tabular}

